\title{
Torsional Behaviour and Finite Element Analysis of the Hybrid Laminated Composite Shafts: Comparison of VARTM with Vacuum Bagging Manufacturing Method
}

\author{
Mehmet Emin Taşdelen, ${ }^{1}$ Mehmet Halidun Keleştemur, ${ }^{2}$ and Ercan Şevkat ${ }^{2}$ \\ ${ }^{1}$ Department of Materials Science and Engineering, Erciyes University, Melikgazi, 38039 Kayseri, Turkey \\ ${ }^{2}$ Department of Mechanical Engineering, Meliksah University, Talas, 38280 Kayseri, Turkey
}

Correspondence should be addressed to Mehmet Emin Taşdelen; metasdelen@gmail.com

Received 1 July 2015; Accepted 7 December 2015

Academic Editor: Antonio Riveiro

Copyright (C) 2016 Mehmet Emin Taşdelen et al. This is an open access article distributed under the Creative Commons Attribution License, which permits unrestricted use, distribution, and reproduction in any medium, provided the original work is properly cited.

Braided sleeve composite shafts are produced and their torsional behavior is investigated. The braided sleeves are slid over an $\mathrm{Al}$ tube to create very strong and rigid tubular form shafts and they are in the form of $2 / 2$ twill biaxial fiber fabric that has been woven into a continuous sleeve. Carbon and glass fibers braided sleeves are used for the fabrication of the composite shafts. VARTM (vacuum assisted resin transfer molding) and Vacuum Bagging are the two different types of manufacturing methods used in the study. Torsional behaviors of the shafts are investigated experimentally in terms of fabrication methods and various composite materials parameters such as fiber types, layer thickness, and ply angles. Comparing the two methods in terms of the torque forces and strain angles, the shafts producing entirely carbon fiber show the highest torque capacities; however, considering the cost and performance criteria, the hybrid shaft made up of carbon and glass fibers is the optimum solution for average demanded properties. Additionally, FE (finite element) model of the shafts was created and analyzed by using ANSYS workbench environment. Results of finite element analysis are compared with the values of twisting angle and torque obtained by experimental tests.

\section{Introduction}

Composite materials are used in a wide range of industrial applications due to their lightweight and high specific stiffness $(E / \rho)$ ratio. They have been widely used for components of aerospace and military airplane structures in their earlier practices. Composite materials are recently used in a lot of commercial applications replacing the conventional materials such as metallic alloys and polymers and it is a fact that the composite technologies have had tremendous development comparing with its earlier situation. New matrix materials and various reinforcing components have led to advanced improvement in the composite technology. At the same time, as it is expected, composite materials and its technology are having great challenges with this extremely high progress.

Shafts are widely used components of machines for transferring the motion and generally they are subject to the torsional cyclic loading in the long range duration; therefore, behaviors of torsion, damping, and corrosion resistance of the materials are main properties to be considered. One of the important alternative candidate materials for shafts can be a composite. Decrease in weight which is provided by using composite materials is leading to reaching high specific stiffness ratio and high rotating speed due to increase in natural frequency. Additionally, shafts made up of polymer matrix composites have some additional advantages with nonmagnetic, small thermal expansion coefficient and high wear resistance.

The studies on composite shafts have nearly 30 -year history $[1,2]$. Composite shafts have been used in various fields such as in marine vehicles [1, 3-5], aviation [6-8], geothermal applications [9], and automotive industry [2, 1016].

The studies done on composite shafts are focused on effects of the mechanical properties, such as torsional behavior, natural bending frequency, and fatigue life, in terms of ply orientation angles, fiber types, and stacking sequences $[7,11,14,16,17]$. Analytical, experimental, and numerical 
TABLE 1: Density and viscosity of the resin and its hardener.

\begin{tabular}{lcc}
\hline & L285 epoxy resin & L287 hardener \\
\hline Density $\left(\mathrm{gr} / \mathrm{cm}^{3}\right)$ & $1.18-1.23$ & $0.93-0.96$ \\
Viscosity $(\mathrm{Mpas})$ & $600-900$ & $80-120$ \\
\hline
\end{tabular}

analyses have been carried out in the studies [16, 18]. Optimal parameters for shaft design and curing cycle effects of resin on torque capacity of hybrid composites shafts have been investigated by various research groups [19-21].

Sevkat et al. investigate the effect of lay-up sequence on the performance of hybrid composite shaft in torsion state, which were manufactured by filament winding technique $[22,23]$. It has been shown that torsional behavior of the composite shaft changes by its lay-up sequence and fiber type. Tate et al. found that tensile and fatigue properties are sensitive to braid angle [17]. Mutasher had found that the static torque capacities of the hybrid shaft could increase via increasing the number of composite layers and fiber types [14]. Badie et al. investigated the effects of fiber orientation angle and stacking sequence on the torsional stiffness, fatigue life, and some other mechanical properties of the shaft [16]. They found that ply angle and stacking sequence has a considerable effect on the buckling torque.

In this study, the effect of fiber hybridization on torsional behavior in composite layer has been experimentally investigated in terms of fabrication methods, which are Vacuum Bagging and VARTM, and different fiber types, glass and carbon. Additionally, the solid modeling of composite shafts has been created and stress analyses have been carried out by using finite element method.

\section{Materials and Method}

Two different types of fibers have been used, carbon and E-glass fibers, for the reinforcement component and epoxy resin; Hexion L285 lamination and hardener, Hexion L287, were used for the matrix structure (Table 1). Carbon and Eglass fibers were in the form of braided sleeves and produced by Barthels-Feldhoff. The braided sleeves were worn on the outer side of aluminum tube having $16.70 \mathrm{~mm}$ of inner diameter and $18.90 \mathrm{~mm}$ of outer diameter. Hybrid composite structure was obtained by changing the stacking sequence of layers and fiber type. Shafts were produced in four different configurations: four-layer glass/epoxy, two-layer glass/epoxytwo-layer carbon/epoxy, two-layer carbon/epoxy-two-layer glass/epoxy, and four-layer carbon/epoxy and Table 2 summarizes configurations of produced shaft specimens. Two production methods which were Vacuum Bagging and VARTM (vacuum assisted resin transfer molding) for each lay-up configuration were performed to obtain different hybrid shafts. Manufactured shafts were kept in the room temperature for 24 hours; then all of the specimens cured at $60^{\circ} \mathrm{C}$ for 16 hours.

Vacuum Bagging method and VARTM (vacuum assisted resin transfer method) were applied as it is defined in the literatures [24-26].
TABLE 2: Configuration of produced shaft specimens for two different production methods.

\begin{tabular}{lcc}
\hline Fiber type & Vacuum Bagging & VARTM \\
\hline${\text { [Carbon }]_{4}}_{\text {E-glass }}$ & $\checkmark$ & $\checkmark$ \\
[Carbon $_{2}+[\text { E-glass }]_{2}$ & $\checkmark$ & $\checkmark$ \\
{$[\text { E-glass }]_{2}+[\text { carbon }]_{2}$} & $\checkmark$ & $\checkmark$ \\
\hline
\end{tabular}

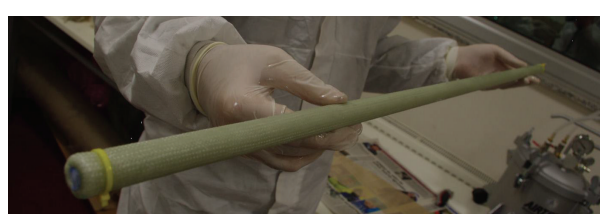

Figure 1: A Vacuum Bagging specimen before the bagging stage.

2.1. Production of the Shafts and Preparing the Test Specimens. The composite components, fibers and resins, were supplied from the same sources for two production methods. Shafts have been made by using the Vacuum Bagging method (Figure 1). All specimens were wrapped in a peel-ply for obtaining a smooth surface at the end stage. The prepared sample which was wrapped in a peel-ply is wrapped by vacuum blanket before the Vacuum Bagging. The vacuum blanket was used to absorb excessive resin on the composite layers. Later, the prepared shaft was placed in a vacuum bag and then vacuuming was started.

The braided sleeves were placed on aluminum tubes without resin in the VARTM method. Later, prepared sample was placed into the vacuum bag and vacuuming was started. While vacuum was applied from one end of the bag, resin was fed from the other end (Figure 2). The vacuum blanket was not used in the VARTM method since excessive resin was aspirated by vacuum. Resin feeding ends were blinded after samples entirely wetted by resin. Samples have been kept under vacuum for 5 hours. Shafts were taken off from the vacuum bags, after the polymerization has been completely done.

2.2. Torsion Test Specimens. All shafts were truncated from two ends into $300 \mathrm{~mm}$ for length alignment. Two ends of the shaft were immersed into the steel square tubes to be able to hold the specimens/shaft onto the torsion test machine. $100 \mathrm{~mm}$ lengths of steel square tubes were adhesively glued up to the specimens/shafts by epoxy resin (Figure 3).

2.3. Experimental Procedure. Static torsion tests were performed by using MTS 215 static and dynamic torsion test machine with max. $25 \mathrm{kNm}$ static torsion capacity (Figure 4). Angle controlled torsion test has been conducted. All hybrid composite shafts were tested at the rate of $0.1666^{\circ} / \mathrm{s}$. Tests were ended with the rapid load loss. All load and angle test data were recorded instantaneously while tests were being performed. A broken test specimen is shown in Figure 5.

The tests were performed under identical conditions with three samples so that the results are reproducible. These data 
TABLE 3: Average fiber orientation angles on each layer for each sequence.

\begin{tabular}{lcccccccc}
\hline \multirow{2}{*}{ Layer sequence } & \multicolumn{2}{c}{$\left[\mathrm{C}_{4}\right.$} & \multicolumn{2}{c}{$[\mathrm{G}]_{4}$} & \multicolumn{2}{c}{$[\mathrm{C}]_{2}+[\mathrm{G}]_{2}$} & \multicolumn{2}{c}{$[\mathrm{G}]_{2}+[\mathrm{C}]_{2}$} \\
& Fiber & Angle & Fiber & Angle & Fiber & Angle $^{\circ}$ & Fiber $^{\circ}$ & Angle \\
\hline Layer 1 & Carbon & \pm 33 & E-glass & \pm 38 & Carbon & \pm 33 & E-glass & \pm 38 \\
Layer 2 & Carbon & \pm 33.5 & E-glass & \pm 40 & Carbon & \pm 33.5 & E-glass & \pm 40 \\
Layer 3 & Carbon & \pm 34 & E-glass & \pm 41 & E-glass & \pm 41 & Carbon & \pm 34 \\
Layer 4 & Carbon & \pm 34.5 & E-glass & \pm 42 & E-glass & \pm 42 & Carbon & \pm 34.5 \\
\hline
\end{tabular}

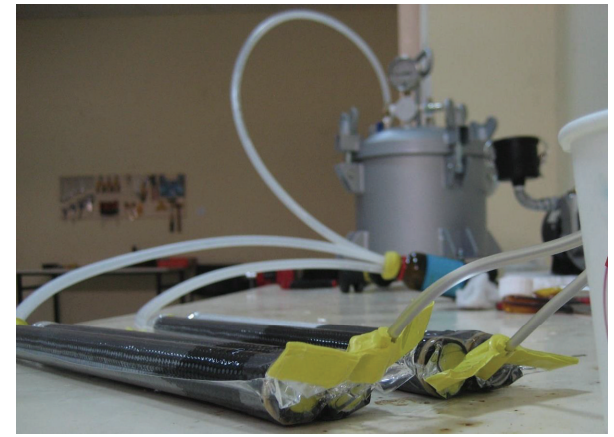

FIGURE 2: VARTM specimens while resin feeding is done by vacuum.

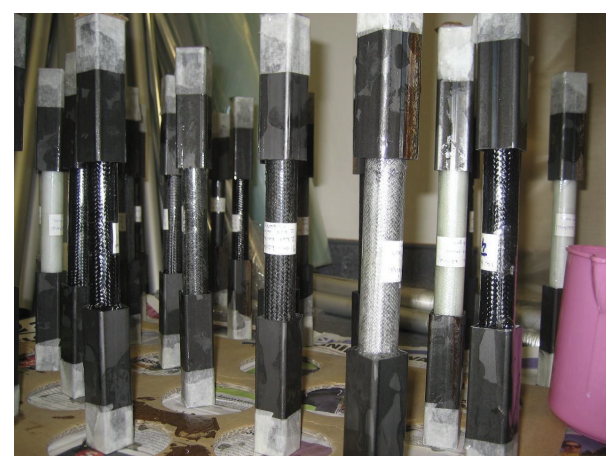

FIGURE 3: Shaft specimens with steel tube fitted to two ends.

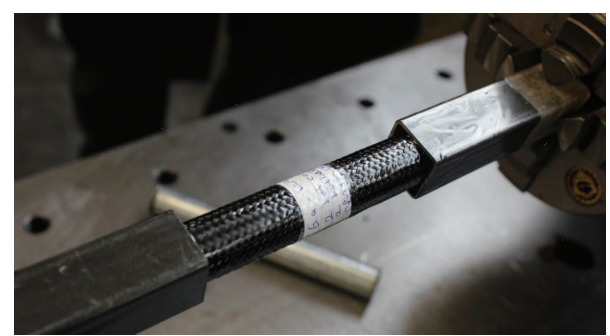

FIGURE 4: A shaft specimen while torsion test is performed.

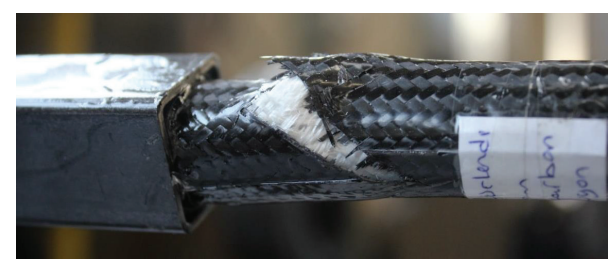

Figure 5: A damaged shaft at the end of torsion test.

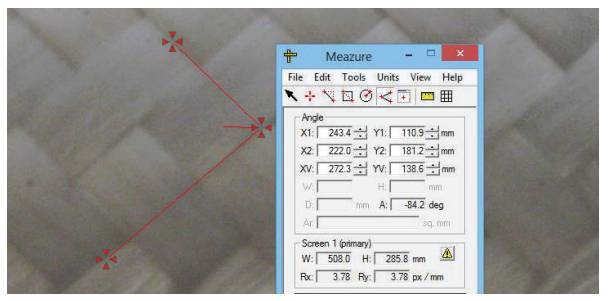

FIGURE 6: Measuring the orientation angle of fiber.

were used for producing graphs for the sake of comparison of results.

Comparisons were made in terms of production methods, VARTM and Vacuum Bagging, and design parameters, the fiber layer stacking order sequence and fiber types. The fiber angle changes layer to layer depending on the outer diameter of the shaft which is increased by composite layers because of using 2D braided sleeves. Therefore, the first layer fiber's angle is smaller than that of last layer. This formation is important for finite element (FE) modeling. All fiber angles of layers were measured by the picture of samples taken during manufacturing. An example picture of on-screen measuring is given in Figure 6. The average fiber angles for each specimen in terms of layer sequence are shown in Table 3.

\section{Finite Element Studies}

ANSYS software code version 14.5 workbench environment was used for creating the solid models and analyzing the torsional behavior. And the following assumptions have been made:

(i) Composite laminates are shell layers.

(ii) Each of the braided sleeves layers is modeled in two shell layers in order to model $\pm \theta$ fiber angle.

(iii) Shaft tube made up of $\mathrm{Al}$ is a linear elastic orthotropic material and it is not included into the solution because of weak bonding with the composite layer.

Linear elastic orthotropic model was used for simulating torsional behavior of composite tubes. Nine elastic constants were determined and implemented in FE model. The linear elastic orthotropic material model was carried out for modeling the static torsion-twisting angle test since it provides an acceptable assumption for highly brittle composite material behavior under torsional loading. FE simulations 


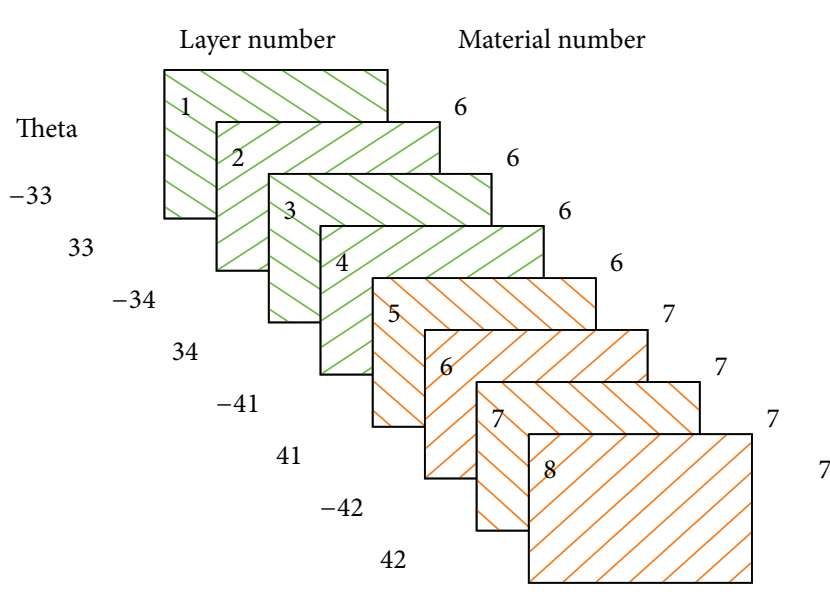

(a)

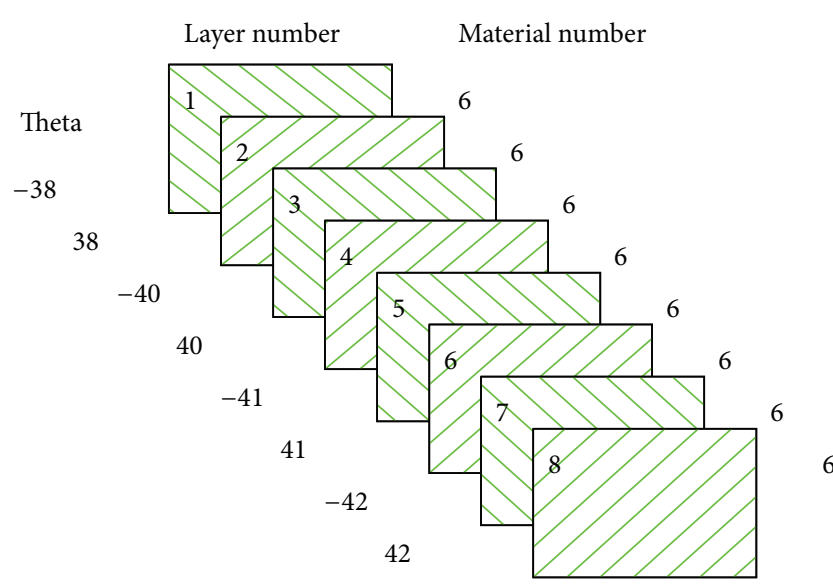

(c)

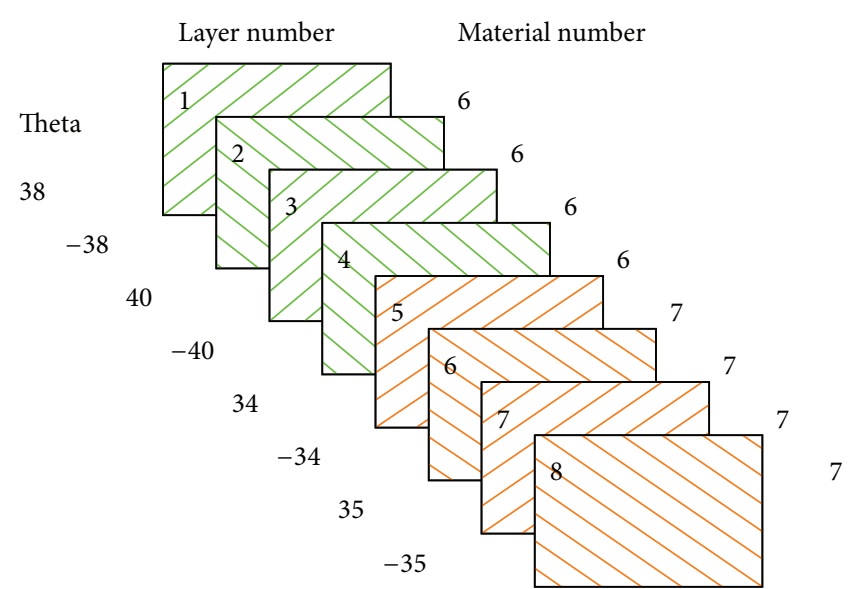

(b)

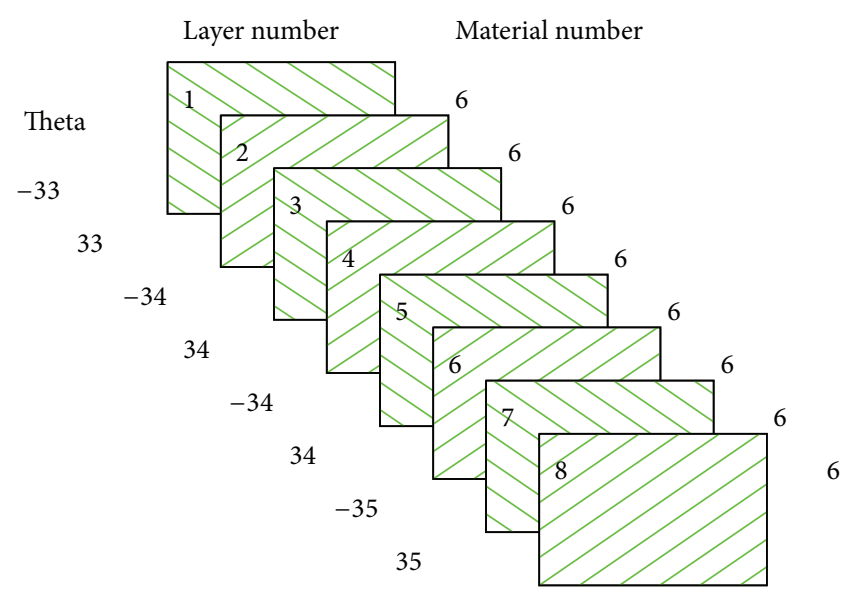

(d)

Figure 7: Lay-up sequences and ply angles of composite shafts. (a) $[\mathrm{C}]_{2}[\mathrm{G}]_{2}$, (b) $[\mathrm{G}]_{2}[\mathrm{C}]_{2},(\mathrm{c})[\mathrm{G}]_{4}$, and (d) $[\mathrm{C}]_{4}$.

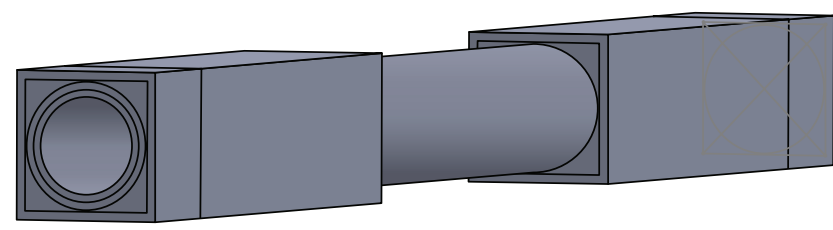

FIGURE 8: 3D model of FE geometry.

were carried out under torque load controlled situations. The maximum applied load for each FE model configuration was chosen considering the level wherein the catastrophic failure happens during the experimental tests. FE simulation models were created for four different stacking sequences similar to the specimens used in experimental studies (Table 2). Each FE model includes eight shell layers for simulating the composite part of shafts (Figure 7). All shell layers have $0.15625 \mathrm{~mm}$ thickness. The geometry of solid model created for FE analysis is given in Figure 8.

Each of the solid models involves 11568 nodes and 11520 elements, for the shell layer. The element type was selected as quadratic for the shell layer, and the element size was adjusted as $1.25 \mathrm{~mm}$. The element type was selected as quad/tri in order to model the grip attachment. Grip sections of models include 12408 nodes and 3360 elements. FE studies were performed on the PC having an Intel Core i5 CPU and 6 GB RAM with the operating system Windows V. 8.0. Approximately, 5 minutes was spent for performing each test.

Engineering elastic constants and Poisson's ratios of the composite laminates were derived by using tensile test results and some analytical relations (Table 4).

In order to obtain Young's modulus at fiber direction $\left(E_{1}=E_{2}\right)$, tensile tests are performed on specimens which consist of only oriented fibers on $x$ and $y$ directions of specimens. The oriented fibers are gained by cutting braided sleeves across to length and then stretched on a plain (Figure 9). Carbon/epoxy and E-glass/epoxy composite tensile test specimens are manufactured with VARTM method and then tested by following ASTM standard which is D-3039 (Figure 10).

The out-of-plane Young's modulus $\left(E_{3}\right)$ is computed by using

$$
E_{3}=\frac{E_{m} E_{f}}{V_{f} E_{m}+\left(1-V_{f}\right) E_{f}} .
$$


TABLE 4: Engineering elastic constants, Poisson's ratios, and density of the carbon and E-glass composites.

\begin{tabular}{lccccccc}
\hline & $E_{1}=E_{2}(\mathrm{GPa})$ & $E_{3}(\mathrm{GPa})$ & $G_{12}(\mathrm{GPa})$ & $G_{13}=G_{23}(\mathrm{GPa})$ & $\nu_{12}(\mathrm{GPa})$ & $\nu_{13}=v_{23}(\mathrm{GPa})$ & $\rho\left(\mathrm{g} / \mathrm{cm}^{3}\right)$ \\
\hline Carbon/epoxy & 32.7 & 6.33 & 2.33 & 2.550 & 0.33 & 0.24 & 1.60 \\
E-glass/epoxy & 20.0 & 6.64 & 2.04 & 2.592 & 0.28 & 0.28 & 1.74 \\
\hline
\end{tabular}

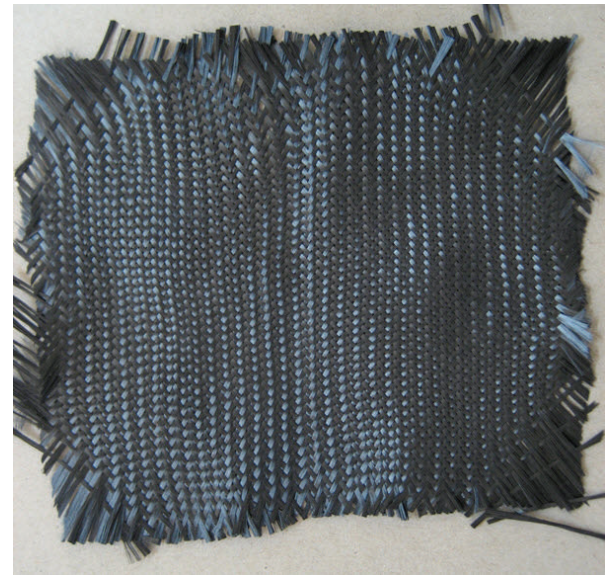

Figure 9: Carbon fiber fabric, derived from braided sleeves.

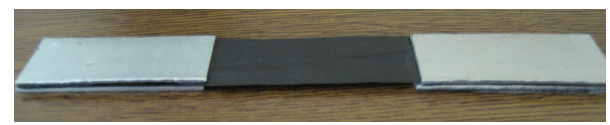

FIGURE 10: Tensile test specimen for carbon/epoxy composite.

Here subscripts $f$ and $m$ represent fiber and matrices, respectively. $E$ is Young's modulus and $V$ is volume fraction.

ASTM D-3518 standard test method is used for in-plane shear response of composite materials $[27,28]$. By the way of tensile test of a laminate, which consists of $\pm 45^{\circ}$ oriented fibers, $E_{x}$ is obtained. Then, in-plane shear modulus is calculated from

$$
G_{12}=\frac{1}{4 / E_{x}-1 / E_{1}-1 / E_{2}+2_{\nu_{12}} / E_{1}}
$$

$G_{13}$ and $G_{23}$ shear moduli are obtained through

$$
G_{13}=G_{23}=\frac{E_{3}}{2\left(1+v_{13}\right)}
$$

Although a shell element was used in FE analysis, in ANSYS the user only has the option of defining orthotropic materials. Therefore, by using 5 independent constants, the remaining materials constants were calculated.

\section{Results and Discussion}

It is well known that the highest stress occurs on the outside surface of the shaft and it decreases inwardly in a torsional loading state for a round specimen. Therefore, it is clear that usages of high strength fiber at the outer shells and low strength fiber at the inner shells will not considerably affect

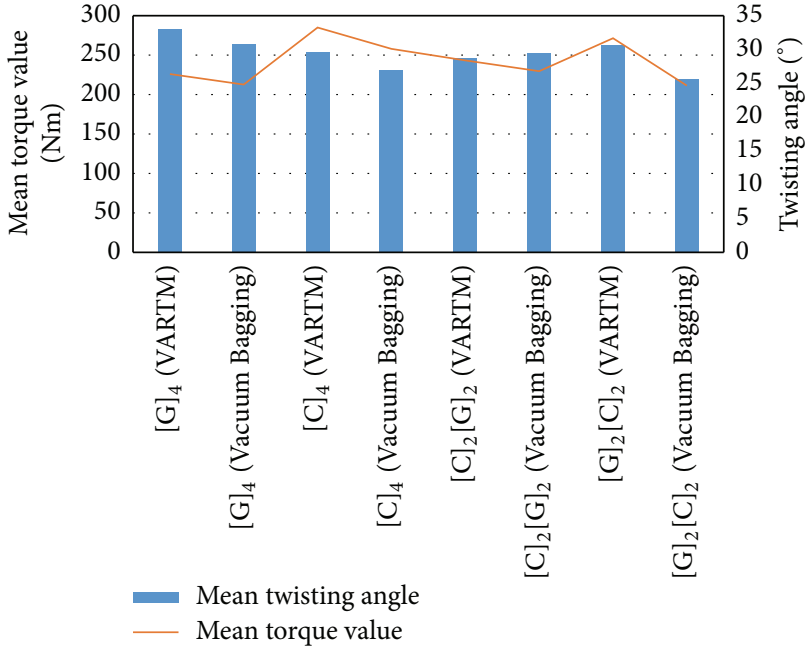

FIgURE 11: Comparison of mean torque and mean twisting angle values in terms of the manufacturing method and lay-up sequences.

the performance of the shaft for the sake of lower cost. By this way, the hybridization of layers can provide an acceptable solution in terms of identical mechanical properties as well. Many researchers have investigated the mechanical properties of hybrid shafts, but the one issued in this study is different from the hybrid shafts studied in the earlier researches in terms of hybridization of composite layers. Mean values of torque capacity and twisting angle obtained during the experimental studies show that the torsional performance of specimens manufactured by VARTM method is much better than those manufactured by Vacuum Bagging method. Figure 11 shows mean torque and twisting angle values of composites manufactured by VARTM and Vacuum Bagging methods in terms of various fiber layer sequences. A better penetration of the resin can be obtained by the VARTM method. Therefore, higher torque capacities of specimens manufactured by VARTM method can be explained with better penetration of the resin between matrix and fibers as seen in Figure 12(a). On the other hand, an insufficient penetration could also be seen in Figure 12(b) as in the case of Vacuum Bagging.

In the VARTM method, usage of a vacuum pump with higher vacuum capacity in order to get higher quality product is crucial for reaching the far end of the mold and maintaining uniformly distribution of the resin in the system. Appropriate resin feeding and vacuum ends should be carefully designed in the manufacturing of the products in which one dimension is comparatively much greater than other dimensions, like pipes and shafts.

Specimens that consisted of only carbon fiber and manufactured by VARTM method show the highest torque capacity 


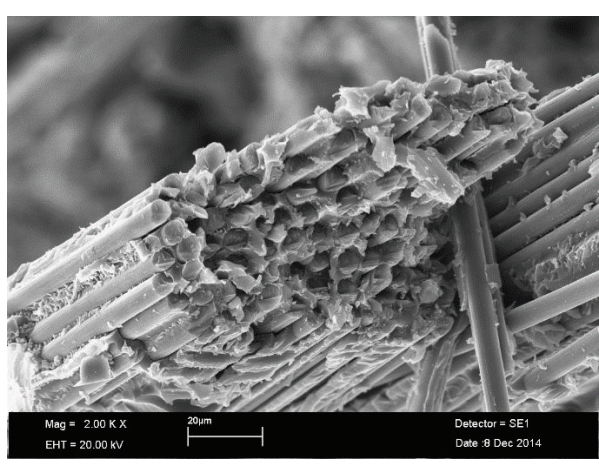

(a)

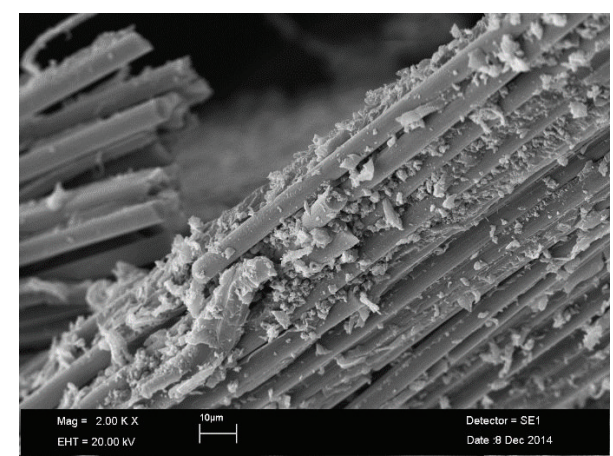

(b)

FiguRE 12: SEM image of VARTM specimen (a) and Vacuum Bagging specimen (b).

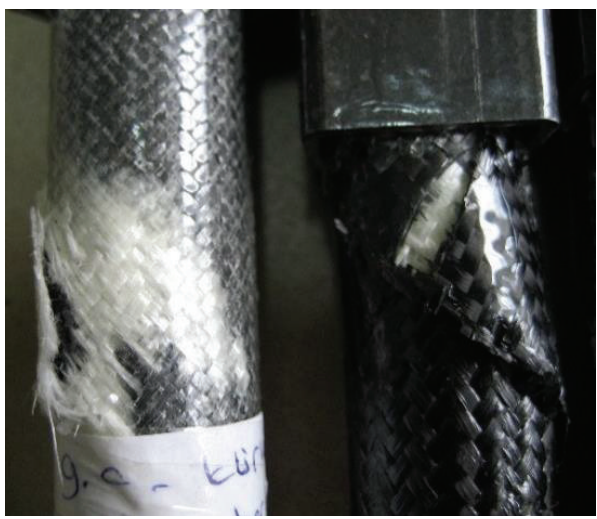

(a)

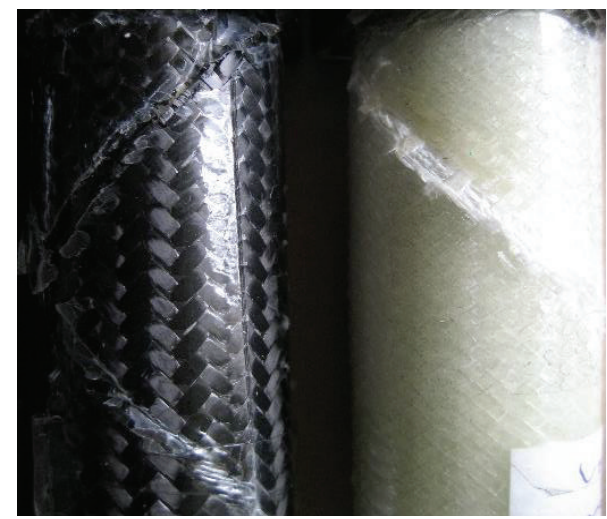

(b)

FIGURE 13: (a) Delaminated hybrid shafts. (b) Single-type fiber used shafts without delamination.

among the rest. The highest torque capacity can be evidently explained considering higher tensile strength and elasticity modules of carbon fiber. The highest failure twisting angle is observed on the specimen consisting of only glass fiber since its tensile strength and elasticity modules are lower than those of carbon fiber. Carbon fibered layers and glass fibered layers are preferred at the outer side and the inner side, respectively, because the highest stress or strain generates on the surface of shaft during the loading; consequently the cost of design will be cheaper with reasonable strength loss on the entire shaft. Torsional test results of shafts with two glass fibered layers at the inner shell and two carbon fibered layers at the outer shell well agreed with this idea. Torsional test results of specimens designed as two glass fibered layers + two carbon fibered layers and particularly manufactured by using VARTM method are very close to those of entirely carbon fibered ones. Torsional test results of specimens with two carbon fibered layers and two glass fibered layers from the interior to the outer shell are not considerably different than those of entirely glass fibered ones. It can be explained that glass fibered layer located at the outer shell is exposed to the stress higher than it can resist and then damages. Therefore carbon fibered layers located at the inner shells cannot elongate simultaneously with the layers made up of glass fiber due to its high elasticity modulus, and delamination occurs between glass and carbon fibered layers during the torsional loading. This situation is viable for both hybridized samples. Even though the delamination could be seen on hybrid shafts by investigating damaged shafts, the delamination has not been noticed in carbon or E-glass made shafts. In Figure 13(a), delamination occurring on hybrid samples can clearly be seen after the torsion test. Thus, delamination has not occurred on samples made fully out of E-glass or carbon fiber; see Figure 13(b).

4.1. Results of FE Modeling. Results of finite element analysis are compared with the values of twisting angle and torque obtained by experimental tests and they well agreed with each other and results are given in Figures 14(a), 14(b), 14(c), and 14(d). The results of specimens manufactured by VARTM method well consisted with the results of FE solution; therefore it can be said that a better manufacturing can be managed by using VARTM method comparing to the Vacuum Bagging method.

The torsional twisting angle of specimens in the experimental results is higher than that of FE results when the results of experimental and FE studies are compared. It can 


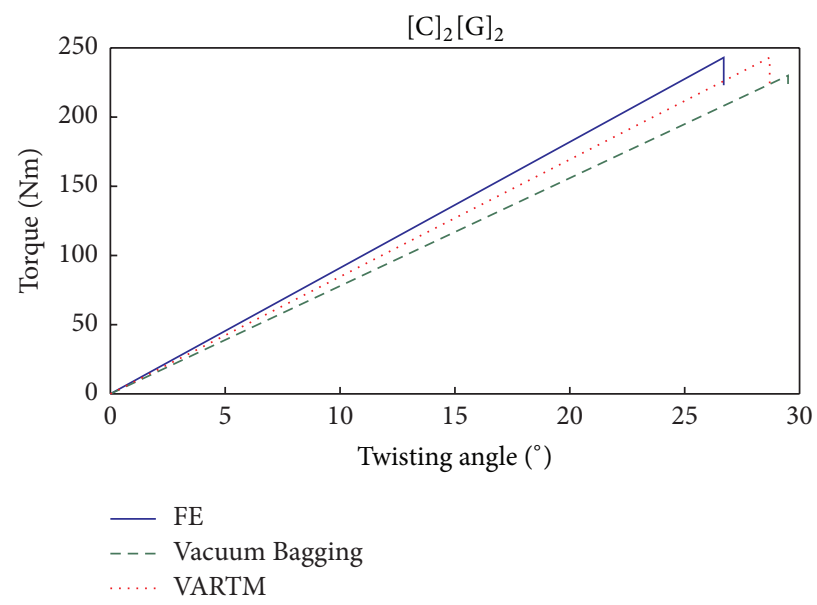

(a)

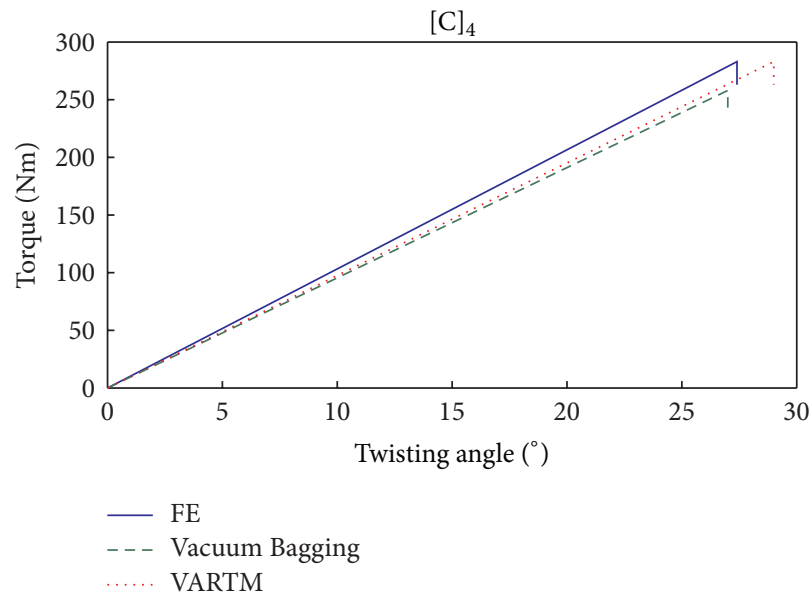

(c)

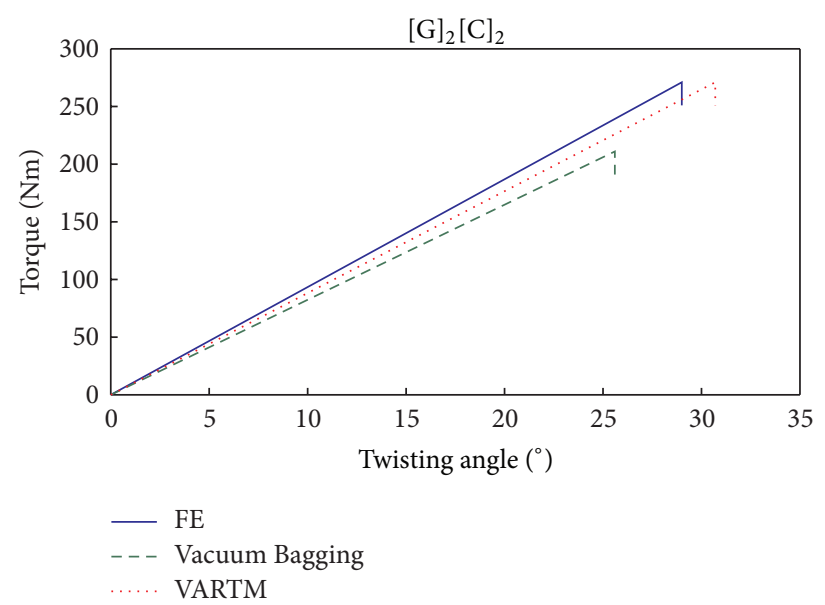

(b)

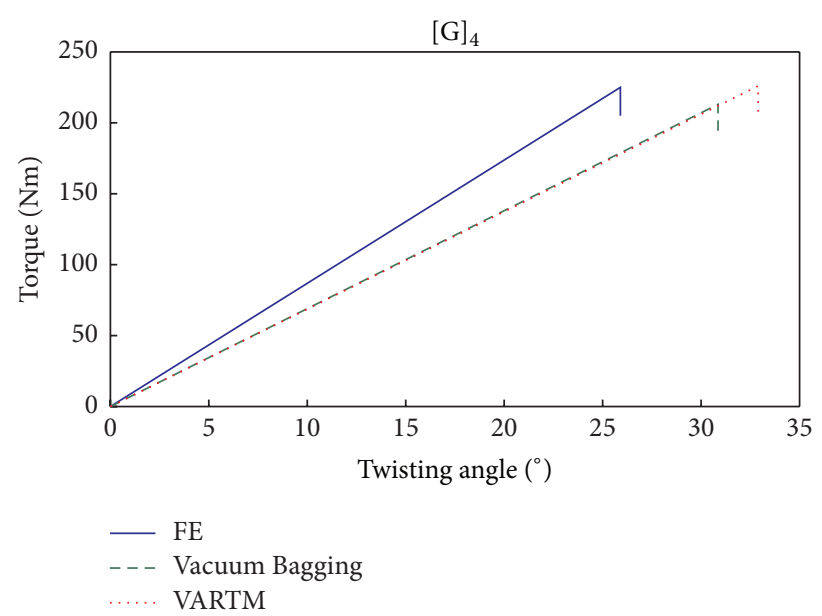

(d)

FIGURE 14: Comparison of the experimental results with FE analysis result. (a) $[\mathrm{C}]_{2}[\mathrm{G}]_{2}$ sequence, (b) $[\mathrm{G}]_{2}[\mathrm{C}]_{2}$ sequence, (c) $[\mathrm{C}]_{4}$ sequence, and (d) $[G]_{4}$ sequence.

be said that the slippage between grips and test specimens during the torsional test might be a reason for this diversity and assumptions made for the FE analysis as well.

\section{Conclusions}

The findings obtained by this study can be summarized as follows:

(i) Braided sleeve fabrics can be used for manufacturing of composite shafts. However, arranging the fiber orientation of plies at desired angle is not possible.

(ii) For the same lay-up sequences configuration, specimens which are manufactured by the VARTM method provide better results than those of Vacuum Bagging specimens, in terms of mechanical properties such as torque capacity or tensile test.

(iii) Hybridization on laminated composite structures can provide great benefits in aspects of cost and performance criteria for the shafts which are subjected to the torsional loading. Selection of the proper fiber type for reinforcement element is an important issue, and usages of strong fibers in the section which is subjected to high strain loads and low strong fibers for the section which is subjected to low strains are other important issues to be considered.

(iv) As a result of the finite element analysis (FEA) of the layered composite shafts, it is noticed that results are promising compared to the laboratory results when using 2-dimensional shell elements in FE modeling. To gain proper results between the analysis and laboratory work, one should comprehend that the elastic constants of composite material must be defined precisely.

\section{Conflict of Interests}

The authors declare that there is no conflict of interests regarding the publication of this paper. 


\section{Acknowledgment}

The authors would like to express their thanks for funding from the Ministry of Science, Industry and Technology of Turkey under Grant no. 00668.STZ.2010-2.

\section{References}

[1] A. P. Mouritz, E. Gellert, P. Burchill, and K. Challis, "Review of advanced composite structures for naval ships and submarines," Composite Structures, vol. 53, no. 1, pp. 21-24, 2001.

[2] S. A. Mutasher, B. B. Sahari, A. M. S. Hamouda, and S. M. Sapuan, "Static and dynamic characteristics of a hybrid aluminium/composite drive shaft," Proceedings of the Institution of Mechanical Engineers, Part L: Journal of Materials: Design and Applications, vol. 221, no. 2, pp. 63-75, 2007.

[3] V. L. Kulakov, N. A. Panfilov, and G. G. Portnov, "Evaluating the feasibility of using composites in ship shafting 1 . Analysis of the loads and stress state of a composite shaft," Mechanics of Composite Materials, vol. 31, no. 6, pp. 565-572, 1996.

[4] V. L. Kulakov, N. A. Panfilov, and G. G. Pormov, "Evaluation of potential composite application in ship shaftlines 2 . Theoretical study of the crack-nucleation threshold and load-carrying capacity of $\left[0^{\circ} / \pm \varphi\right]$ laminated composites loades in shear and uniaxial tension or compression in the reinforcement plane," Mechanics of Composite Materials, vol. 32, no. 1, pp. 39-47, 1996.

[5] J. S. Tate, A. D. Kelkar, and J. Rice, "Feasibility study of VARTM manufacturing of carbon biaxial braided composites using EPON 9504 epoxy resin system," in Proceedings of the 8th Japan International SAMPE Symposium, pp. 1145-1148, Tokyo, Japan, November 2003.

[6] B. Spencer and J. McGee, "Design methodology for a composite drive shaft," in Proceedings of the Advanced Composites Conference, Dearborn, Mich, USA, December 1985.

[7] J. S. Tate, A. D. Kelkar, and V. A. Kelkar, "Failure analysis of biaxial braided composites under fatigue loading," in ECF15, Stockolm 2004, 2013.

[8] E. C. Botelho, R. A. Silva, L. C. Pardini, and M. C. Rezende, "A review on the development and properties of continuous fiber/epoxy/aluminum hybrid composites for aircraft structures," Materials Research, vol. 9, no. 3, pp. 247-256, 2006.

[9] M. Tanoğlu and M. Toğulga, "Kompozit malzemeler ve jeotermal uygulamaları. VI. Ulusal Tesisat Muhendisliği Kongresi (Teskon)," in Jeoternal Enerji Doğrudan Isıtma Sistemleri; Temelleri ve Tasarımı II. Seminer Kitabı E/2003/328-4, pp. 407-419, 2003.

[10] Z. Đorđević, S. Maksimović, and I. Ilić, "Dynamic analysis of hybrid aluminum/composite shafts," Scientific Technical Review, vol. 58, no. 2, pp. 3-7, 2008.

[11] Y. A. Khalid, S. A. Mutasher, B. B. Sahari, and A. M. S. Hamouda, "Bending fatigue behavior of hybrid aluminum/composite drive shafts," Materials \& Design, vol. 28, no. 1, pp. 329-334, 2007.

[12] D. G. Lee, H. S. Kim, J. W. Kim, and J. K. Kim, "Design and manufacture of an automotive hybrid aluminum/composite drive shaft," Composite Structures, vol. 63, no. 1, pp. 87-99, 2004.

[13] D. H. Cho, D. G. Lee, and J. H. Choi, "Manufacture of onepiece automotive drive shafts with aluminum and composite materials," Composite Structures, vol. 38, no. 1-4, pp. 309-319, 1997.

[14] S. A. Mutasher, "Prediction of the torsional strength of the hybrid aluminum/composite drive shaft," Materials \& Design, vol. 30, no. 2, pp. 215-220, 2009.
[15] M. M. Shokrieh, A. Hasani, and L. B. Lessard, "Shear buckling of a composite drive shaft under torsion," Composite Structures, vol. 64, no. 1, pp. 63-69, 2004.

[16] M. A. Badie, E. Mahdi, and A. M. S. Hamouda, "An investigation into hybrid carbon/glass fiber reinforced epoxy composite automotive drive shaft," Materials \& Design, vol. 32, no. 3, pp. 1485-1500, 2011.

[17] J. S. Tate, A. D. Kelkar, and J. D. Whitcomb, "Effect of braid angle on fatigue performance of biaxial braided composites," International Journal of Fatigue, vol. 28, no. 10, pp. 1239-1247, 2006.

[18] K. Xu and X. W. Xu, "Finite element analysis of mechanical properties of 3D five-directional braided composites," Materials Science and Engineering A, vol. 487, no. 1-2, pp. 499-509, 2008.

[19] H. S. Kim, S. W. Park, H. Y. Hwang, and D. G. Lee, "Effect of the smart cure cycle on the performance of the co-cured aluminum/composite hybrid shaft," Composite Structures, vol. 75, no. 1-4, pp. 276-288, 2006.

[20] T. Rangaswamy, S. Vijayarangan, R. Chandrashekar, T. Venkatesh, and K. Anantharaman, "Optimal design and analysis of automotive composite drive shaft," in Proceedings of the International Symposium of Research Students on Materials Science and Engineering, pp. 1-9, December 2002.

[21] C. Ruegg and J. Habermeier, "Composite propeller shafts design and optimization," in Advances in Composite Materials, pp. 1740-1755, Pergamon Press, Paris, France, 1980.

[22] E. Sevkat, H. Tumer, M. H. Kelestemur, and S. Dogan, "Effect of torsional strain-rate and lay-up sequences on the performance of hybrid composite shafts," Materials \& Design, vol. 60, pp. 310319, 2014.

[23] E. Sevkat and H. Tumer, "Residual torsional properties of composite shafts subjected to impact loadings," Materials \& Design, vol. 51, pp. 956-967, 2013.

[24] J. A. Maley, An Investigation into Low-Cost Manufacturing of Carbon Epoxy Composites and a Novel "Mouldless" Technique Using the Vacuum Assisted Resin Transfer Moulding (VARTM) Method, Carleton University, Ottawa, Canada, 2008.

[25] H. Saito and I. Kimpara, "Evaluation of impact damage mechanism of multi-axial stitched CFRP laminate," Composites Part A: Applied Science and Manufacturing, vol. 37, no. 12, pp. 22262235,2006

[26] C. Wittman and G. D. Shook, "Hand lay-up techniques," in Handbook of Composites, G. Lubin, Ed., pp. 321-367, Springer, New York, NY, USA, 1982.

[27] R. M. Jones, Mechanics of Composite Materials, Taylor \& Francis, 1998.

[28] E. Sevkat, B. Liaw, F. Delale, and B. B. Raju, "Drop-weight impact of plain-woven hybrid glass-graphite/toughened epoxy composites," Composites Part A: Applied Science and Manufacturing, vol. 40, no. 8, pp. 1090-1110, 2009. 

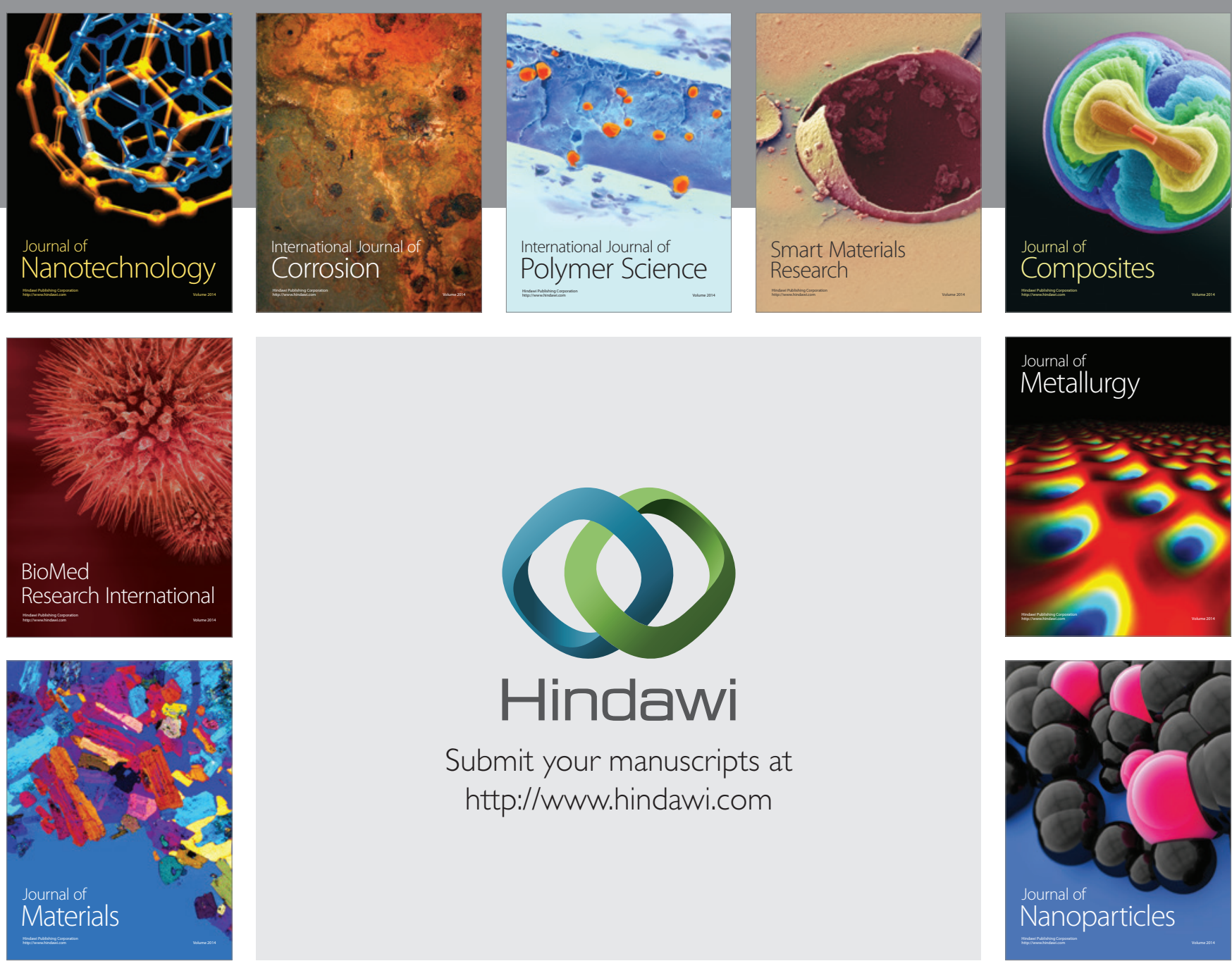

\section{Hindawi}

Submit your manuscripts at

http://www.hindawi.com

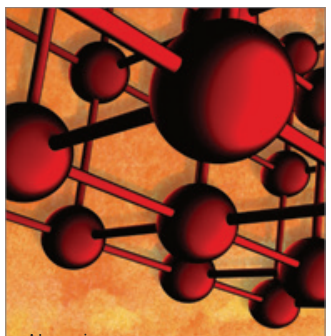

Materials Science and Engineering
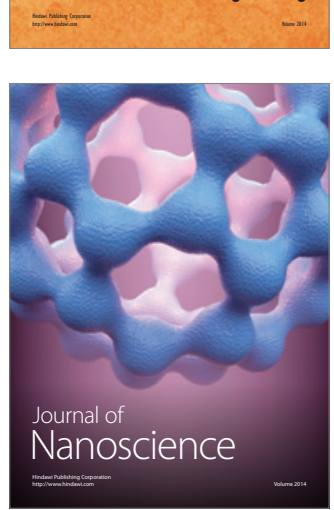
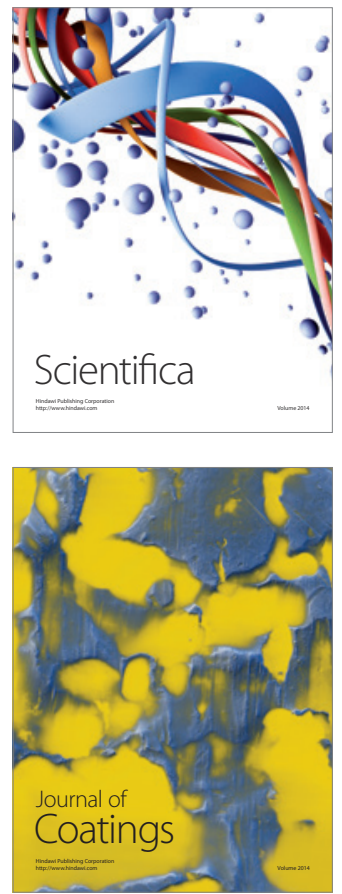
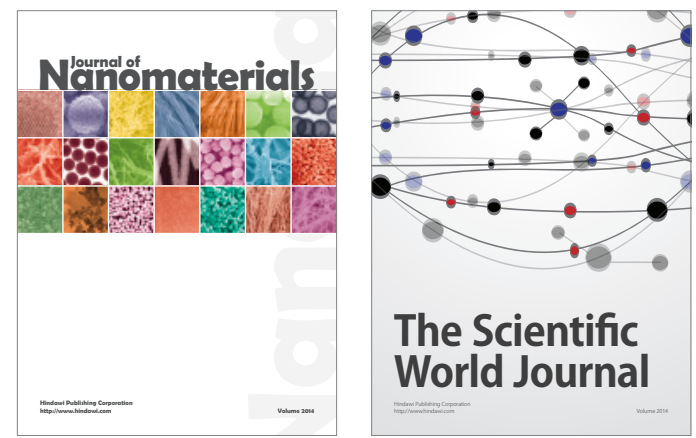

The Scientific World Journal
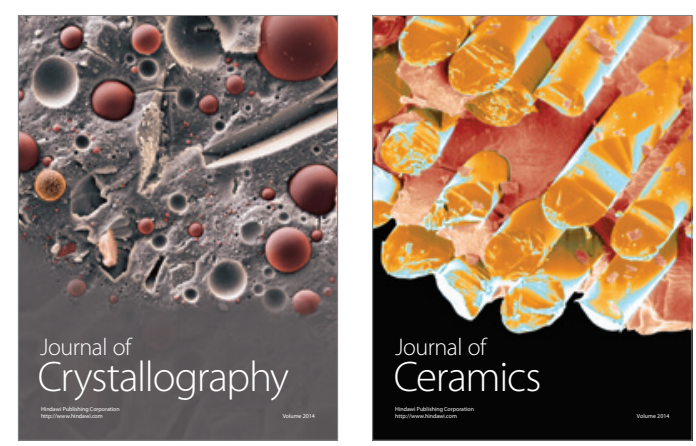
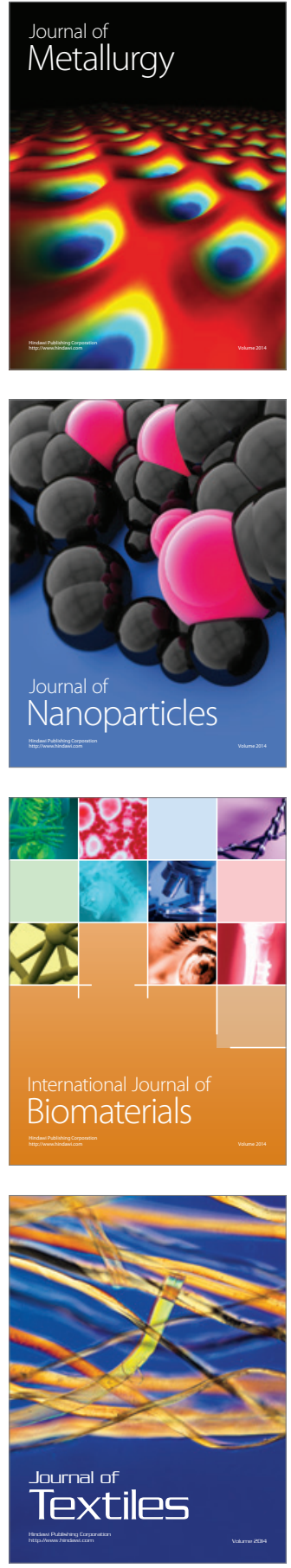